\title{
YouTubers, Online Selves and the Performance Principle: Notes from a Post-Jungian Perspective
}

\author{
Greg Singh ${ }^{1}$
}

University of Stirling, UK

doi: $10.5937 /$ comman11-11414

Abstract: Of the many challenges facing the field of media studies today, the rapid acceleration of the media ecosystem through which people communicate, share and indulge, and seek escape from the tedium of everyday life, presents a set of specific problems. The contemporary media landscape is both an extension and a continuation of more traditional forms and objects for analysis, and also an arena that has, arguably, radically redefined the discipline in terms of the innovations and stark changes to technology, institutions and financial arrangements that have shaped the world of media and communications as we know it. A key area in which post-Jungian approaches are well-placed to accommodate is in the fast-changing field of online media celebrity. The meteoric rise in popularity of YouTube vloggers has given new impetus to the fields of celebrity studies and persona studies - redefining the popular understanding of how celebrity status is sought, conferred, and consumed; and ultimately, transforming how celebrity is defined as a notion. Using critical inquiry as a method, this article discusses mediatised notions of self, persona, and self-commodification from post-Jungian and relational perspectives. The discussion from these theoretical perspectives will open vistas into the critical study of digital, networked media, as well as affording the possibility of an intensification of the critique from psychological and psychoanalytic perspectives on contradictions and tensions present in such contexts.

Keywords: celebrity, YouTube, Jung, Marcuse, recognition, performance, selfpsychology

\footnotetext{
1 Contact with author: greg.singh@stir.ac.uk.
} 


\section{Introduction}

On $16^{\text {th }}$ August 2007, a YouTuber calling himself "shaycarl" posted the first of what would become several hundred videos ('Fun with Helium and Passing Out'). Subsequently, during the course of 2008, shaycarl incorporated his family into regular posts. Over time, he also introduced viewers to his family's lifestyle and domestic environment. The SHAYTARDS YouTube channel has an impressive 4.8 million subscribers at the time of writing. ${ }^{2}$

Mirroring the transformation of rock star brands such as Alice Cooper, the public entity ("Shaytard") has become synonymous with an individual person (Shay Carl Butler). This unlikely comparison illustrates the metonymic conflation of public celebrity and private individual that often occurs in celebrity culture: fans and avid YouTube subscribers often refer to Butler simply as "Shaytard", in the same way that fans refer to Vincent Furnier as "Alice Cooper". This practice outlines the continuity in the association of YouTube practices, and celebrity culture in general. It also reflects the psychology of personality in public life. In particular in online contexts, but also in celebrity culture at large, personality is a shorthand for public entities of a kind that embody what is understood in media studies and marketing discourse as 'media property' or 'brand presence', and all of the values associated with those terms. ${ }^{3}$

It is worth noting that, even with his impressive CV, Shay Carl Butler is a virtual outsider in orthodox media studies. However, Lagore (2015) and Lashley (doctoral thesis 2013) both write about the importance of Butler and his work at the intersection of traditional media, television and celebrity studies perspectives. Having researched psychoanalytic studies of various schools, I can find no mention of him or his various enterprises and in fact, at best, the discipline offers wafer-thin coverage of Web 2.0 celebrity culture in general, just as psychoanalytic approaches to celebrity culture in more established, vested media such as television, cinema or publishing have often been found wanting. Where psychoanalytic approaches have attempted to deal with the digital, as

\footnotetext{
November 2016.

3 Butler's main YouTube channel, SHAYTARDS carries links to ShayCarl, ShayLoss (a vlog dedicated to Butler's weight loss journey over the course of several years), a dedicated website, as well as all of the major social media platforms; Shay Merch - the website hosting a clothing and merchandise store with connections to Trixin, an apparel range owned by Butler; and Maker Studios, Butler's substantial convergent media production company, originally set up in 2009 and acquired by Disney in 2014 for an amount reported to exceed $\$ 500$ million dollars in cash, plus options (Spangler, 2014).
} 
Balick (2014a) suggests, all too often "thinking stops". ${ }^{4}$ Processes of engagement, co-production and meaning-making in online communication practices are part of the fabric of everyday lives in popular culture, but when thinking continues (rather than stops) one can see clear parallels between these processes, and the processes found in psychoanalysis, as well as various practices of relational and other therapies.

This implies that a meaningful dialogue between media studies and psychoanalytic studies on the interface between celebrity, technology and selfhood in popular culture is long overdue. The aim of this article is to set up such a dialogue in three directions. These directions work through a critical framework of post-Jungian persona (1953) and Winnicott's false self (1956), Aaron Balick's essays of relational psychology in the online world (2014a, 2014b), and Herbert Marcuse's work on the politics of recognition and performance (1955).

The first of these directions intends to map out, for non-specialists, the contemporary media ecosystem as an accelerated, convergent realm of connectivity, particularly in relation to YouTube as the popular media platform for celebrity existing today. ${ }^{5}$ indicate salient issues where a post-Jungian perspective can form insights into that ecosystem. The second direction will be to engage the psychology of personality in terms of the way in which consumer-users engage with and mobilise online identity in such accelerated contexts. This will be done through a critical discussion of theoretical frames, including Jung's concept of persona, Winnicott's notion of the false self, and the presentation of the self in interpersonal exchange, applied in Web 2.0 contexts. The third direction I wish to pursue considers how relational processes concerning the negotiation of private and public lives in Web 2.0 contexts function to accommodate the contradictions associated with apparent opposites in play (the opposites re-

\footnotetext{
${ }^{4}$ As an aside, there is some crucial reflection as to why this happens - psychotherapist Mick Cooper, for example, identifies research that considers various kinds of online therapy, and the kinds of factors that impact upon its effectiveness (2008). One prevalent attitude regarding the effective therapeutic space is the psychotherapy room as a space free of technological impingement; and it is therefore easily understood in this context why psychotherapy in practice often views the social media world with suspicion - as an invasion of psychological space that can get in the way of the healing process. In my view, this is precisely the reason why a collection such as that found in this special issue of CM seems like such a departure from orthodox subject matter for psychoanalytic studies - and is entirely justified as a crucial intervention in the field of digital media phenomena.

5 According to its own press release for statistics, YouTube has over a billion unique users; and 'every day, people watch hundreds of millions of hours of YouTube videos and generate billions of views.' The streaming service also reaches more 18-34 and 18-49-year-olds than any cable network in the U.S. https://www.youtube.com/yt/press/en-GB/ statistics.html [Accessed: 28/10/2016].
} 
ferred to here are experiential distinctions and similarities in online and real-life identity). Here, I draw from Marcuse's notion of performance principle - his attempt to account for the excess materiality associated with politics of recognition, and the need for the human psyche to accommodate this in dialogue with reality and desire. The discussion in these directions will open critical vistas into the study of digital, networked media, as well as affording the possibility of an intensification of the critique from psychological and psychoanalytic perspectives on the contradictions and tensions present in such media contexts.

\section{Mapping Problems of an Accelerated Media Ecosystem}

Of the many challenges facing media studies today, the rapid acceleration of the media ecosystem through which people communicate and share, and seek escape from everyday life seems to be central (see, for example, Cunningham, Craig \& Silver, 2016). This acceleration effect presents a set of specific problems. While the contemporary media ecosystem is both an extension and continuation of more traditional media forms, it has also redefined the discipline of media studies in terms of thinking about how innovations in technology and their relationship with end-user behaviours shape the world of media and communications as we know it. Sherry Turkle (2011) and danah boyd (2012) have both used the term "always-on" to describe a state of persistent, semipermanent connectivity where being part of a network connected to people and information, wherever and whenever, is assumed. This state has transformed both the character and immediacy of social interactions, and fundamentally, a sense of who I am, and 'where' that 'I' might exist.

This situation precipitates a major concern for media studies scholars who are interested in psychological and humanist approaches to media. My own perspective is shaped by innovations in the field of post-Jungian depth psychology and its potential to provide an understanding of the psychic, unconscious and archetypal processes at work in the production and consumption of culture. Whereas post-Jungian ideas have been applied to a number of arts and humanities fields, perhaps most successfully in film theory and criticism, there are at present still very few post-Jungian or depth-psychological interventions in the field of contemporary digital media cultures. Notable exceptions to this include edited collections (e.g. Weitz, 2014), a special issue of The Spring Jour- 
nal on the theme of technology, cyberspace and psyche (Winter, 2008), and book-length studies (Balick, 2014b; and Singh (forthcoming).

A key area in which post-Jungian approaches would be well-placed is in the fields of celebrity and persona studies. In particular, the meteoric rise in popularity of YouTube vloggers (such as Zoella, Pewdiepie, Smosh, Caspar Lee, Miranda Sings and shaycarl) has given new impetus to these fields, helping to redefine the popular understanding of how celebrity status is sought, conferred, and consumed; and ultimately, transforming how celebrity is defined (see Biressi \& Nunn, 2010; Chen, 2016; Click, Lee \& Holladay, 2013; Davis, 2013; Driessens, 2013; Hill, 2014; Jerslev, 2014; Marshall, 2014; Rojek, 2015; Stever, 2011). Whereas a number of formative studies on YouTube, performance and identity have facilitated debates in this area that are largely confined to orthodox media studies concerns (Snickars \& Venderau, 2009; Lange, 2014; Burgess $\&$ Green, 2009), there are some efforts that focus on emotional and parasocial connections (Walker Rettberg, 2008, 2014; Papacharissi, 2010, 2011; Baym, 2010). Because of its focus on archetypal and archetypical notions of persona, post-Jungian thought can provide an insight into the dynamics of performance of self, and of blurred public and private distinctions in collective psychological encounters. Whereas there are studies on Youtube celebrities, and on YouTube's emotional and relational aspects, there are few psychoanalytic perspectives. Such perspectives might offer something valuable to the understanding of networked media, particularly in its Web 2.0 iteration.

As Jose van Dijck writes, "Between 2000 and 2006, quite a few media theorists claimed that Web 2.0 applications exponentially enhanced the natural human need to connect and create, and they declared early victory for the user" (2013: 10). Such an explicitly utopian discourse on social media empowerment is noticeably less common in the current recuperative climate where increasing and accelerating media concentration has led to the centralisation of a very few massively-influential "siren servers" (Lanier, 2013). Therefore, YouTube, far from being a Web 2.0-optimised 'pull' medium where the "produser" is king (Bruns, 2008), is in some ways significantly aligned with the push mechanisms associated with concentrated, top-down broadcast media forms; and gatekeeping practices more akin to vested interests of capital, than to democratic ideals.

According to Snickars and Vendereau (2009), since Google's acquisition of YouTube in 2006, the discourses associated with the platform have changed 
markedly from the championing of entry-level amateur productions of everyday activities to a quest for 'quality' content, with Google ushering in a new era of monetisation as the "no. 1 priority of 2009" (YouTube Fact Sheet, cited in Snickars \& Vendereau, 2009: 10). Of course, there is still no shortage of cat videos and badly-framed clips of cute babies on the platform. However, in the context of 2016, you are as likely to get this kind of content from an alreadyknown celebrity as you are from a member of the general public; and alongside professionally produced content (that is sometimes feature length, rather than mere clips), often on the same channel.

However, this tension between the Web 2.0 ethos of inclusion and the quest for better content as a "no. 1 priority" merely refers to front-end, 'plug-in-andplay' consumer experiences. The back-end of these convergent media services - which are made up of massive amounts of personal data, held in datasets, which are almost exclusively of a proprietary nature and ultimately unusable in the hands of the ordinary end-user - ensures that the average consumer has very little knowledge of these processes, let alone has access to that data in a readable and usable form (Zelenkauskaite, 2016). This amounts to a systematized abnegation of users' ownership of their own personal information and, on the part of the platform, is a systematically and structurally disempowering institutional arrangement. It is reasonable to assume that the average consumer would have little interest in pursuing such access: even with a basic awareness of such arrangements of information flow, consumers of such convergent media forms are satisfied ${ }^{6}$ with the trade-off of personal data for goods and services (Markos, Labrecque \& Milne, 2012). Furthermore, there are an increasing number of studies that seek to deal with the aftereffects on users' habits and attitudes towards convergent Web interaction (Fuchs, 2012, 2014; Fuchs et al., 2014; Meikle \& Young, 2012; Hogan, 2010).

From these perspectives, the individual as such has become part of the content being produced. Purpose-built algorithms designed to draw out data to increase the efficiencies of reach and identify safe areas for investment only serve to accelerate this direction of movement. In essence, the ordinary user is the product. Content, in this sense, can be taken as front-end social media profile and browser/click-through patterns, through mid-points of consumer profiling, to

\footnotetext{
${ }^{6}$ At least, satisfied in the instrumental sense of receiving gratis access to key mass communications platforms, subject to accepting terms and conditions.
} 
back-end data production. In this way, contemporary media interaction has taken on (to borrow from classic Marxian terminology) the appearance-form of consumer-as-agent, which sublates a deeper, atomised version of consumer-ascommodity, and tends to reduce the character of customer satisfaction to the choice of trade-off: access to media services for a surrender of data. This is, essentially, an estranged relationship with a set of popular practices and activities to which users generally devote considerable amounts of their time. ${ }^{7}$ It renders more holistic notions of labour, and indeed subjectivity, as unfit for purpose (the 'purpose' here being bottom-line leveraging of surplus value), unless such labour and subjectivity can be wholly quantified.

\section{Self-Presentation and the Public-Private: Relational Perspectives}

This process of the commodification of users has been the subject of scholarly attention, as outlined. However, the related-but-separate notion of self-commodification, where users self-identify publicly with specific lifestyle choices, and document these extensively on platforms such as YouTube or in connected social media, is more immediately relevant in the context of celebrity YouTubers and their followers. For example, documenting one's FitBit data or an Instagram of one's healthy breakfast, or vlogging about one's experience of a fitness challenge are commonplace. This self-disclosure practice is also illustrated when consumer-users post links to personal lifestyle material via the comments section on a celebrity's YouTube channel. This expresses, in a public space, a parasocial commonality with that celebrity. Whereas distinct public and private spaces do exist today, and are valued according to their own qualities, there is also something new in the conceptual sense where public and private distinctions are no longer upheld as conventions of social relationships, and intimacy is signified through a kind of public-private interchangeability on social media platforms. In this latter scenario, we are dealing with worldviews aligned to everyday mediatised experiences, negotiated through a sort of consent within the relations of labour, consumption and exchange outlined above, and shaped through values associated with celebritization (Driessens, 2012, 2013).

7 Krüger \& Johanssen (2014) discuss this at length in relation to alienation and digital labour. 
Far from being a purely technological phenomenon in the conventional sense, these issues are fundamentally tied to notions of identity and presentations of self in everyday life. However, these notions are amplified exponentially in the context of interpersonal communications via YouTube and other Web 2.0 platforms that facilitate self-commodification through extensive online documentation. This amplification reveals contradictions running through the heart of YouTube as a platform for identity mobilisation, as seemingly opposite notions of public and private are suspended, as are other seemingly dichotomous elements such as the ordinary on the one hand, and the extraordinary on the other.

Such tensions between public and private, ordinary and extraordinary, are especially interesting in terms of YouTube celebrity because its effectiveness often relies upon striking a balance between extremes. It emphasises at specific moments one over the other, but more often than not extremes are held in a delicate suspension. A basic requirement of vlogging is that it presents for the viewer an ordinary person who can be related to on some personal level, at least in the first few posts before the vlogger is established as a 'personality'. Conventions often include being framed in a talking-head shot, in an everyday setting, making observations about the quotidian and being relatable to the audience.

This was the case with Shay Carl Butler. His pronounced physical transformation over time via a very public weight-loss challenge was matched by heavily self-publicised changing family arrangements. New members of his family were born into his publicly-viewable lifestyle, and alongside Butler's own vlogging professionalization, his family members became professional vloggers too. The contradictions of celebrity and everyday were also reflected in the choice of environments within which the vlogs were produced - from conventional talking-heads posts to shopping trips in Times Square, and even more tellingly, a vlog posted from a media industry award ceremony to which his whole family was invited. The change in presentation (if not production values, which remain resolutely DIY for the majority of his posts) reflects the mediatized journey that shaycarl has undertaken since 2007 . The contradictory elements suspended in this celebrity-driven media ecosystem are intertwined spectacle and everyday life, and public and private identities.

For Luke Hockley (2014), this "flowing together" of public and private aspects of our identities, and the way we come to regard ourselves and others, 
allows a psychological space of consideration for the messy, lived complexity of social phenomena. I would take this further in suggesting that, in contemporary image-driven culture, and within the persistent connectivity associated with the always-on, the way that humans as intersubjective beings tend to engage in their dealings with one another amplifies this complexity. This lived complexity is as important for spaces of imagination as it is for social spaces of communication, and by extension, the co-produced relationships between individuals and groups in the social and imaginal realms. In the context of cinema and cinema cultures, for example, Hockley (2014: 35) states that:

"Jung used the term enantiodromia [...] to suggest that opposites, far from pulling in different directions, in fact turn out to run into each other. When seen in this light it is apparent that the cinema is both a place of psychological encounter yet equally provides a safe space for this encounter to happen."

He writes that this pulling together of seemingly contradictory terms is essential to engage the role of culture in determining the expression of collective psychological encounters: "[...] in keeping with post-Jungian theory, which aims not to establish a lack (as in Freudian and particularly Lacanian theory) but rather to find a productive tension in bringing what might appear to be opposites together" (Hockley, 2007: 14).

Perhaps the most productive tension in the context of YouTube personalities and celebrity cultures is the blurred distinction between public and private in the identification, construction and mobilisation of the self. The immediacy and sheer speed of exchange, amplified through emotionally-charged celebrity culture, and engaged with by consumers of popular culture who are not only fans (and anti-fans, haters) of the celebrity figures themselves, means that consumer-users tend to be adept with the discourses featured in the communicative practices of platforms. Things tend to escalate very quickly under such intense circumstances. The GamerGate phenomenon illustrated this tendency with alarming results.

GamerGate started out as a Twitter hashtag response to a viral blog post, uploaded by software developer Erin Gjoni in August 2014. In the post (known colloquially as 'The Zoe Post', and widely distributed on several online sites and chat forums, including 4chan) Gjoni detailed his relationship with ex-partner Zoe Quinn, an independent game designer. Subsequent commentary and re- 
sponses from readers of this blog, mainly from the crossover of gaming culture and 'Men's Rights Activism', led to allegations that Quinn had given a games journalist sexual favours in exchange for a favourable review of her free-to-play game, Depression Quest (Poland, 2016; Stuart, 2014; Kolhatkar, 2014). It later transpired that the critic had never reviewed the game, but the train of events spiralled out into widespread death and rape threats on several social media and chat sites, doxxing (the publication of personal data of Quinn and members of her family) and even the release of nude pictures of Quinn on so-called 'revenge porn' websites (Busch, Chee \& Harvey, 2016). As Keith Stuart (2014) reported in the Guardian at the time:

"[...] proponents of this movement say their key target is games journalism. Gamergate complains about cronyism between certain writers and developers [...]. The undercurrent, however, has always been darkly misogynistic. The victims of Gamergate's ire have mostly been female developers, academics and writers."

Although it has largely disappeared from popular cultural view, GamerGate has remained more than a mere Twitter hashtag. For Shaw and Chess (2016) it is a constellation of website activities - across Tumblr, redditt, the 4chan and 8 chan forums, the subject of memes, and also of crucial importance to its longevity, a persistent presence across several YouTube channels. The voracity, extremity and self-belief, for example, that Gamergaters have displayed in their dedication to discrediting female videogame developers, critics and commentators is deeply troubling in its aggression (MacCallum-Stewart, 2014; Poland, 2016). Well-known examples of this practice of trolling-as-a-lifestyle goal include the relentless attacks upon 'Tropes vs. Women in Video Games' Youtuber and 'Feminist Frequency' vlogger, Anita Sarkeesian (Kolhatkar, 2014; Chess \& Shaw 2015). Indeed 'Men's Rights Activist' YouTubers such as NateTalksToYou, Thunderf00t, and dozens of others have devoted entire YouTube series to discrediting her work; comments on their posts often appear to endorse crossing multiple social boundaries to attack Sarkeesian on a personal level, punctuated with sexually violent language towards her or her family (Poland, 2016).

The position of Sarkeesian as a public intellectual rests upon her professionalized use of Web 2.0 technologies to pursue and leverage audience reach. Her success is such that demands for content have seen Sarkeesian crowdfunding future work through Kickstarter campaigns. This itself has led to criticisms of 
her work ranging from drifting away from her video essay DIY roots, to criticisms of her using fans' money for her own private gain (Kolhatkar, 2014). At this purely technical level, Sarkeesian cannot win: her opponents use the same productions conventions as weapons to undermine her position. At another level, the professionalized nature of her opposite numbers is in itself astonishing. Using the same levers and monetisation tactics as those attacked, these YouTubers have established norms in harnessing parasocial mechanisms of both identification and alienation to facilitate parallel careers.

They present as 'reality' - the logic of such right-wing critics relies on an appeal to facts, logic and 'keeping things real' to succeed. But even at a superficial level, the levels of constructed self-presentation enacted by both bloggers and commenters are similar. Sarkeesian, for example, presents as a public intellectual and critic. Her critics, when forming full critiques of her work, tend to use similar presentation techniques and conventions to present their cases. In the Sarkeesian case, as in other right-wing YouTuber cases, this even produces instances where fan videos are made in tribute to critics (e.g. dedicated to $\mathrm{Na}$ teTalksToYou) of so-called 'Social Justice Warriors'. The point here is that the escalation into what can only be described as hate-filled practices on free speech platforms, ironically predicated on a perceived need to shut someone down, is sped up through the capabilities of the platform itself, and through appropriation of similar conventions to those used by the targets.

The parasocial involves the application of unsaid protocols informing appropriate behaviours and responses in such contexts. In the case of a YouTuber's interaction with users, this is a one-way system in the first instance, particularly in such massively popular cases as Shay Carl Butler. However, the public and private distinction is not merely a matter of deception: it is an everyday description of an interplay between a number of levels operating within social encounters. Firstly, a number of conventions are invoked through a setting, for example, affordances of the medium, comment-enabled exchanges; generic codes and conventions associated with the content of the posted videos; and discourse associated with the short forms of communication held to be standard in comments posted on YouTube, and the emotional discourses associated with celebrity more generally (aspiration, admiration, infatuation etc.). Secondly, through what might be described as a proxemics of YouTube, social psychology approaches serve to illustrate the added complexities of social context 
cues, the level of communication fidelity, non-verbal communications clarity, the absence of eye-contact in non-visual communications forms, and so on (e.g. Sproull \& Kiesler, 1986; Joinson, 2003). Thirdly, levels of trust and anxiety management (Gudykunst, 1995) are made more complicated through the character of emotional investment associated with fannish devotion to particular YouTube personalities. Finally, from a post-Jungian perspective, impression management might be described as a normal, 'everyday pathology' regarding this misrepresentation.

In this sense we might consider the intersubjective dimensions of interpersonal encounters and the presentation of a 'version' of oneself - phenomena described by post-Jungian and relational schools as the presentation of a mask or false-self of some kind.

\section{Jung's Concept of Persona}

When Jung $(1953 ; 1921 / 1998)$ described the notion of persona, he referred to it as a psychological archetype of social adaptation. This persona is not 'false' in quite the same way as a 'fake', or as an inauthentic or imaginary construct, or as a vehicle for intentional deceit. ${ }^{8}$ The main point in classic Jung is the emphasis on the dangers of over-identifying with one's persona. He saw this as coming at the expense of deep self-development in the sense of an unconscious process. He also saw this in terms of the labels that are given us by others in social situations - labels that 'stick', and are internalised. It is not so much the misrepresentation that is problematic here, but the proclivity for human subjects to fully identify with the misrepresentations involved. Crucial to fully understanding the presentation of self, therefore, is the acknowledgement of the role of persona (the aforementioned 'mask' or 'false-self') in such contexts.

The key schools of thought in relation to persona and false self are the postJungian and relational traditions associated with Winnicott (1956). For Aaron Balick (2014b), the Jungian persona and the relational false self are expressions of ego functions, because "they both lie between internal experience (intrapsychic) and the outside world (intersubjective); hence, they can both be conceived

\footnotetext{
8 Although, it is perhaps worth noting that deception might be thought of in the sense of a conceptual category related to aspects of all of these descriptions insofar as the archetype existing as part of the self's psychological defences against both the degradation of the continuity of self, and social ineptitude.
} 
as 'relational' because they develop for the purpose of managing the space between self and other" (2014b: 16).

Jung's own description of persona also reveals and emphasises the relational aspects of this function. For Jung (1998: 99, my emphasis), the persona is a

"[...] functional complex that comes into existence for reasons of adaptation or personal convenience, but is by no means identical with the individuality. The persona is exclusively concerned with the relation to objects. The relation of the individual to the object must be sharply distinguished from the relation to the subject."

This concern with objects is key to understanding the Jungian dilemma of persona. In the first instance, the essence of persona is relational, in that it forms an interface in the way people communicate and socialise. It enables the functioning of interpersonal protocol in social settings. In this model of selfpresentation an individual can present to others a version of themselves they deem appropriate to the given situation. However, the Jungian model emphasises the unconscious, psychic function of this 'versioning' process - vital for the health of ordinary social relations and the psychic wellbeing of the individual. This is because it is an ongoing process, occurring alongside and supporting every social interaction within which we participate. It is at least the function (if not exactly the same form) of what Winnicott (1956) described as a 'false self'. He wrote (1956: 387) that

"This false self is in no doubt an aspect of the true self. It hides and protects it, and it reacts to the adaptation failures and develops a pattern corresponding to the pattern of environmental failure. In this way the true self is not involved in reacting, and so preserves a continuity of being."

Jung made similar observations when he wrote that, as the social face an individual presents to the world, persona is a complicated system of relations; "[...] a kind of mask, designed on the one hand to make a definite impression on others, and on the other to conceal the true nature of the individual" (1953: 190).

Therefore, one may see similarities between Jung's notion of persona and Winnicott's false self, where the hidden character of the encounter with selves is elaborated. Not foregrounded, but made apparent, through a comparison of these descriptions in both lines of thought is a discernible enantiodromic 
running-together of an impression-intention and a concealment-intention. It is true that concealment has negative connotations associated with deception and acts of anti-social behaviour. However, concealment also provides for a hiding, a protection, which, although present in Jung's notion of persona, is made much more explicit in Winnicott's notion of false self. Both systems attempt to account for the dialogical complexity of interpersonal presentation and impression management in social contexts, and Balick's work draws from the relational aspects of both to create a three-dimensional sense of how these encounters work in online social communications.

For Balick, persona is suited to the individual: even as it distorts the view of the true self for others, it is never fully a false self that is presented. In this sense, both Jung's and Winnicott's systems account for a relation to a partial accuracy. Therefore, the term 'false' is not intended to signify 'inauthentic'. Inauthenticity ought to be reserved for cases where the individual identifies with the false self as if that is all there were. For Balick, "Pathology develops only when the individual identifies with their persona at the expense of other attributes of their personality: when they believe the persona to be 'the whole thing"' (2014b: 16).

It is not a straightforward matter to reconcile conceptualisations of persona and false self as being the same in terms of form. Winnicott's false self is very much an aspect of self that one might relate to the notion of identity, whereas Jung's persona needs to be considered as a more fundamental adaptation archetype. Therefore, while it is fair to say that they are not the same, I would argue that they are related nonetheless. ${ }^{9}$

This matter leads us to the second instance in Jung, and his concern with objects specifically. Where there is over-identification of an individual with their persona, as can happen in the everyday psychology of personality, this misrecognition has implications for the differentiation in consciousness between individual and person, which Jung took pains to distinguish in his essay on Psychological Types (1971). In human interactions, healthy personae are characterised by both robustness and strong differentiation. However, social media

\footnotetext{
9 Some schools of relational thought, particularly Kohut's self-psychology (1977, and elsewhere), and Jacoby's reading of Kohut and Jung (2006) articulate the similarities and differences in these two conceptions with remarkable clarity, using relational terminology to describe the articulation of self and identity. I have little space to dedicate to this matter here. However, it is worth stating the value of Kohut's work in this regard as an under-explored area for developing a robust theoretical framework for online identity. I discuss his work in more detail elsewhere (Singh, forthcoming). I ought to acknowledge a debt of gratitude here to Luke Hockley, who introduced me to Kohut's work some time ago.
} 
communications have an in-built tendency for communication shorthand, and this tendency systematically favours the personally convenient, and the immediacy of identification with persona as a quick-response, 'easy version' of the self. On this basis, assumed versions of oneself and others have a tendency to become estranged; and relations become objectified. This bears out in Lupton's work on the quantified self (2016), which considers the layers of objectification and profiling in self-tracking processes - ultimately governed through routines of data automation, rather than necessarily through user agency. Self, in this sense, is systemic and simulated, rather than expressed in any strong sense by the user; and these routines are the governing principle at the data level in all social media platforms, YouTube included.

The function of persona as social interface is a description of relational aspects of interpersonal communication, and also has an intrapsychic function. As Balick notes: "Both the [Winnicott model of] false self and [Jungian] persona function in an outside-facing way by utilising the reality principle to prevent id-oriented aims" (2014b: 16 [my emphasis]). Here Balick overtly uses Freudian terminology to articulate tensions inherent in the self-identity dynamic, where the self is partially founded upon basic drives - something Jungian psychotherapists sometimes refer to as 'affectivity'. ${ }^{10}$ However, there are further questions to be addressed regarding how these intrapsychic processes are transformed in routines of a commodified-self. For example, how does this self become sublated by relations between individuals and personae to appease the needs of what might be described as a performance principle?

Balick makes a similar argument largely in the context of identity expression though front-end profile information (status updates, field form information in comments, etc.). However, a thicker description is possible regarding the nature of this identification at the data level - where the extent of consumeruser agency is curtailed even further by regimes of automation and filtering that go largely unchecked and are invisible to users. Not only is there a danger that users will identify with the presentation on social media as the whole thing, but social media itself, through its algorithms and filtering mechanisms, identifies the profiled user as the whole thing. Innovations such as semantic media and artificial intelligence may be ingenious, but they do not and cannot constitute human consciousness as a recognising presence in the same sense.

\footnotetext{
${ }^{10}$ For example, C.T. Stewart refers to affectivity as the "primary motivation system in humans, the energy behind all agency", expressed as "innate affects" (2008: 5).
} 


\section{YouTube Celebrity, Reality Programming and the 'Performance Principle'}

In this light, I contend that the commodified self, addressed through routines of automation (such as targeted advertising, suggested links, recommendations and so on) experiences an estrangement from the world of the social at the level of data profiling. There are a number of precedents outlining this direction of argument (e.g. Krüger \& Johanssen, 2014; Andrejevic, 2011), particularly in relation to affectivity. From my perspective, data profiling as a practice and process actively encourages the Jungian pathology of persona identification; in classical terminology, this automated commodification of identity comes at the expense of the 'soul' or psyche of the consumer. In a less poetic description it is an affront to the notion of agency in an everyday sense and runs counter to assertions that participation in social media can lead to strong freedoms of expression.

This is also the case at the more front-end level of online interpersonal encounters, where the performed version of the self is the version presented to, and acknowledged by, the other, in mutual exchange. There is a doubling effect to the character of this estrangement where the individual over-identifies with the false-self presented in interaction with other false-selves. In this way, doubling occurs in an amplifying circle of estranged social relations and recognition politics. This is a kind of compliance towards the state of affairs inherent in the system, in which the compliant self carries with it the very real danger of potential for misrecognition by individuals, groups and society as representative of the whole thing.

The important issue is not so much the fact that people have a false self or persona, but that SNSs are geared towards emphasising these aspects of intentionality and agency over and above others. Whereas Jung and Winnicott account in different ways for the problems associated with over identifying with persona and the false self, the converse is also true. We see this in the disinhibited behaviours of fans commenting on their favourite YouTube videos, where they open themselves up to the extent that they become vulnerable to uncaring, toxic responses. ${ }^{11}$ Ultimately, this points to another dialectic - in relation to performed intimacies and public shows of affection in fans' comments towards

${ }^{11}$ Such practices of self-disclosure are the subject of a range of scholarly approaches to social media behaviours (boyd, 2014; boyd \& Donath, 2004; Baym, 2010; Papacharissi, 2010; Walker Rettberg, 2008 and 2014), and so I will 
their YouTube celebrities. The nature of this parasocial performance is connected to the maintenance of a specific impression that adheres to conventions of public presentation. This points again to the tension between authentic and inauthentic, where distinctions between the private self and public persona are marked by a perceived authenticity of the former, and a relative inauthenticity of the latter. Erving Goffman, whose work is influential in the field of social media studies, writes (1997: 22-23 [Lemert and Branaman eds.]) that

"In their capacity as performers, individuals will be concerned with maintaining the impression that they are living up to the many standards by which they and their products are judged. [...] But, qua performers, individuals are concerned not with the moral issue of realizing these standards, but with the amoral issue of engineering a convincing impression that these standards are being realized."

There is a standardization or convention of behaviours, emphasising the version of the self as performed to be the specific object intended for the other party's attention, rather than standards in any moral sense. It has been pointed out (e.g. by Athique, 2013) that this might in itself lead to a superficial or diminished interpersonal exchange, because of Goffman's implication that there is an 'original' self, lying at the heart of personality - the performed version is something quite apart. However, this does not fully engage the reciprocal intrapsychic nature of the versioning process as maintaining an accommodation of inner and external worlds (within the social imaginary), and the space that Goffman himself gives over to this reciprocation. Goffman goes on to state that, "At one extreme, one finds that the performer can be fully taken in by his own act; he can be sincerely convinced that the impression of reality that he stages is the real reality" (1997: 95). This is, of course, an internalisation, of the performed version of the self as 'the whole thing' - the very phenomenon that both Jung and Winnicott guard against. The immediacy and semi-permanence of the contemporary media ecosystem not only affords such practices, but actively rewards them.

This is found especially in practices of celebrity YouTubers themselves, whose success often depends upon the creation of strong and stable mythologies about their own personal journeys - an interaction standard as much as a

not explore them in too much detail here, except to observe the relatively obvious and underexplored avenues for considering public displays of intimacy and disclosure from a post-Jungian perspective on the false self and persona. 
skilled narrative - to build fan viewership over the course of several videos. In some cases, this journey can take years. It involves a performed, explicitly stated conviction that one is on a journey; and this conviction in turn encourages endusers to invest emotionally in the notion that they are sharing that journey $-\mathrm{a}$ telos embodied by the metaphor of a journey. In a protracted series of vlogs over the course of several years, shaycarl gives his weight-loss 'journey' extensive coverage. These materials detail Butler's reflective experience of starting out, gaining conviction and a sense of mission, achieving goals, overcoming stumbling blocks and so forth. The conviction with which Butler dedicates himself to bodily transformation is concomitant with his steady rise to fame. The corporate "mission" to which he applies his efforts is both well-documented, and received with enthusiasm amongst his fans. The more they engage with his work, the more his fans are rewarded with further content. This might be said to be the case for much of the transmedial content produced in the contemporary media ecosystem, which is, by a general rule of thumb, reliant upon the convergence of media platforms and the synergy involved at the level of industrial and corporate convergence (Jenkins, 2006; Jenkins, Ito \& boyd, 2015). However, in the context of YouTube's specific role in Maker Studios' output, these interactions mask, at barely a hair's breadth, the underlying secondary effects of this journey - that all of the activity generates phenomenal amounts of data about end-users, which is quantified into information, and is convertible into surplus value of specific interest to YouTube as a corporate platform, and therefore Maker Studios' business model.

There are other kinds of performances in celebrity YouTuber activities. Some are more discernibly theatrical and performative to the user-consumer than the kinds of performances that are constructed as 'real' (I refer to the Shaytards here as a typical example of the latter). In such cases the performances are presented as deliberate, and often, deliberately awful. The synthetic nature of this may be summarised as parody or at the very least, a playful interaction with the conventions and values associated with the platform, and the end-user is both fully aware of the levels of performativity, and the direction in which the joke is aimed.

A clear example of this kind of performance can be found in the work of another popular YouTuber, Miranda Sings (played by Colleen Evans). The function of Miranda's performance is not to deceive the audience, but to play 
on conventions of reality programming forms. Miranda's shtick is to perform popular songs, in an act where she is convinced of her popularity due to being such a likeable YouTuber (she is purposively neurotic, over-sensitive, irritable and generally unlikeable) and a pop star in the making (her renditions are deliberately awful). In this case, the target of the parody is both the concept of YouTube celebrity itself, and the presentational form through which standards impress their meaning through gesture, iconography, and generic convention. In this sense, then, Miranda's persona is much more playfully in tune with formal aspects of drag performance, and certainly operates at a level of campness that is both knowing, and excessive. Evans has her own YouTube channel (PsychoSoprano), ${ }^{12}$ has produced vlogs specifically addressing the artifice embedded in the Miranda performance e.g. make-up tutorials on how to emulate Miranda's look ('Becoming Miranda Sings!' published Feb 22, 2013) and often breaks the illusory authenticity of Miranda through appearing simultaneously as both herself and Miranda, using split-screen technology. ${ }^{13}$

We may think about the nature of Evans' performance in a number of ways, operating at different levels in terms of interacting with the platform itself (YouTuber performance, end-user performance in comments etc.). However, one might begin to take this interaction further, by considering Herbert Marcuse's notion of performance principle. This idea moves criticism towards the implications of how the technical mechanics of practices found in the interactions of presentation, misrepresentation, quantified profiling and emotional investment in YouTube engagements interact at the level of the psychological. His approach lends itself to a political economic trajectory of the psychological projects that find root in both Jung and Freud. The performance principle, according to Marcuse, is the "prevailing form of the reality principle" (1955: 35) and can therefore be said to characterise a development of Freud's original concept, which dates back to his "Formulations Regarding the Two Principles of Mental Functioning" essay (1911), itself claimed by Vannoy Adams (2004: 1-2) to be a development of Jung's work, "Concerning Two Kinds of Thinking” (also 1911).

It is intriguing to think about Marcuse's work in relation to firstly, the performativity of social media interactions within routines of data automation and

\footnotetext{
${ }^{12}$ As of October 2016, Miranda has featured in her new Netflix Originals series 'Haters Back Off.

${ }^{13}$ For example, 'Miranda and Colleen Q+A', posted Feb 10, 2015; and 'Miranda and Colleen sing together!' posted Jan 31, 2013.
} 
governance (i.e. a quantified self) and secondly, the performance of self at the level of subjective encounter (i.e. YouTube 'personalities'). The way Marcuse describes his notion of performance principle could have been written with these two factors in mind. He is worth quoting in full (1955: 45) here:

"The performance principle [...] presupposes a long development during which domination has been increasingly rationalized: control over social labor now reproduces society on a large scale and under improving conditions. For a long way, the interests of domination and the interests of the whole coincide: the profitable utilization of the productive apparatus fulfils the needs and faculties of individuals. For the vast majority of the population, the scope and mode of satisfaction are determined by their own labor; but their labor is work for an apparatus which they do not control, which operates as an independent power to which individuals must submit if they want to live. And it becomes the more alien the more specialized the division of labor becomes. Men do not live their own lives but perform preestablished functions. While they work, they do not fulfil their own needs and faculties but work in alienation."

As with most Marxian approaches, work in the sense that it is necessary to subsist is superseded here by a kind of work that is surplus to that need - the digital labour of social media users, who produce monetised data sold at a remove to third parties. Simultaneously, such labour is performed in relation to another kind of work - the labour of YouTube personalities and their public relations teams, in co-ordinating the production of content and enriched pathways to merchandising and third party sites and other revenue strategies. Ironically, although the industrialized nature of this activity may be classed as another kind of surplus work because of its inherent estrangement from the products of individuals' labour, it is also performed, in the sense that it serves the purpose of professionalized activity for the individual 'personalities' involved.

The distinction Marcuse implies between work that is needed for one's satisfaction and work that is needed for the apparatus happens to coincide, fulfilling the career needs of the YouTuber, and the profit needs of industrial sponsors, of various descriptions. However, the instrumentalized relations through which the YouTuber-as-a-worker tends to, and supports, the needs of the apparatus involved (a content platform to generate user-interest for the purpose of monetising their data) is doubly estranged when bringing the status of the other 
YouTube worker (the end-user) as a product into the equation. If YouTubers themselves are conforming to the needs of the apparatus through content production and the performance of conventions associated with professional vlogging, YouTube end-users are also conforming to their own assigned roles as commodified objects. When applied to this relationship in social media relations of production-consumption, one can see how the notion of performance principle can help describe how desire is manipulated to establish what Marcuse (1964) described as one-dimensionality - the one-dimensionality of a commodified self, or a false self, or, in the over-identification with persona as the whole thing. The parasocial aspects of relationships formed in social media contexts alone give rise to aspects of desire-fulfilment that are necessary as a step (one among many) towards that instrumentality.

\section{Conclusion}

The extremes of performance of self that Goffman suggests are in some ways deconstructed by the playful conventions of vlogging, such that whereas no-one in particular is deceived by a performed act or character, we are also as audiences no longer required to hold such performances in cynicism. Networks on YouTube become more like nebulae in that the apparatus through which to read performances becomes ever more subtle and nuanced, just as the performances themselves become more standardized and conventional over time.

In the final analysis, there are a number of political questions that need to be addressed further. Political economy critique of the role of data profiling in relation to the quantifying and commodification of selves in social media contexts has established itself in media studies (e.g. Dyer-Witheford, 1999, 2010; Allmer, 2015). Parasocial approaches to social media interaction are also emerging as key themes for critical theory to develop (e.g. Bocarnea \& Brown, 2007; Click, Lee \& Holladay, 2013; Stever, 2011). Theories of parasocial phenomena, and the emotional investment built through such interpersonal relationships with unknown and unknowable public personalities, tend not to feature in political economy approaches and vice versa; and therefore neither paradigm alone adequately foregrounds the social imaginary of connectivity within platforms such as YouTube, as a rich psychosocial space for critical inquiry and further exploration. 
Data profiling as a process actively encourages what Jungian perspectives consider the pathology of persona identification; and in classical Jungian terminology, data profiling comes at the expense of the 'soul' or psyche of the consumer. There is a sense in which this description holds true in its poetic, experiential sense. The trade-off argument in Web 2.0 discourse (goods and services are gratis, with the proviso that end-users give up certain rights to control data associated with their activities, movements, opinions, meaning, and even world-views) very rarely goes so far, except perhaps in circumstances where critics take more polemical stances towards the status quo. Although there is a danger here of reproducing the notion of an authentic/inauthentic binary, what is needed, perhaps, is a holistic, enantiodromic approach to the notion of what might constitute an inauthentic self, particularly in response to the need for a more dynamic and dialectical consideration of self and identity relations in online interpersonal communications.

In terms of a politics of recognition and the commodification of identity mobilisation in online communications, there is a question concerning the practices of 'versioning' that YouTube practices seem to lay bare, as a goaloriented performance towards quantified status - and the professionalization of such performative practices. The character of professionalization of vloggers primarily working on YouTube ${ }^{14}$ reflects the wider cultural shift in Web 2.0 from creating and expressing as aspects of democratised communicative practice, to the monetising and industrial recuperation of technologies and practices as ends in themselves. This much has been commented upon and critiqued by various segments of the political spectrum (Jenkins, Ito \& boyd, 2016; Lovink 2011, 2016; Dyer-Witheford, 1999, 2010; van Dijck, 2013). What I hope to have outlined in this article are three directions of the performance of online selves that may be explored further, and in turn, for which post-Jungian and relational schools of thought might shed further light.

${ }^{14}$ Zoella, Sprinkleofglitter and other big-name celebrity vloggers in the field of fashion, lifestyle and cosmetics are perhaps typical here. 


\section{References}

Allmer, T. (2015). Critical Theory and Social Media: Between Emancipation and Commodification. London: Routledge.

Andrejevic, M. (2011). Surveillance and Alienation in the Online Economy. Surveillance \& Society, 8(3): 278-287.

Athique, A. (2013). Digital Media and Society. Cambridge: Polity

Balick, A. (2014a). How to Think about Psychotherapy in a Digital Context. In Weitz, P. (ed.), Psychotherapy 2.0: Where Psychotherapy and Technology Meet (pp. 23-40). London: Karnac.

Balick, A. (2014b). The Psychodynamics of Social Networking: Connected-up Instantaneous Culture and the Self. London: Karnac.

Baym, N. (2010). Personal Connections in the Digital Age. Cambridge: Polity.

Biressi, A. \& Nunn, H. (2010). "A Trust Betrayed": Celebrity and the Work of Emotion. Celebrity Studies, (1) 4: 49-64.

Bocarnea, M. C. \& Brown, W. J. (2007). Celebrity-Persona Parasocial Interaction Scale. In Reynolds, R. A., Woods, R. \& Baker, J. D. (eds.), Handbook of Research on Electronic Surveys and Measurements (pp. 309-312). Hershey, PA: Idea Group Reference.

boyd, d. (2014). It's Complicated. London: Yale University Press.

boyd, d. \& Donath, J. (2004). Public Displays of Connection. BT Technology Journal, 22(4): 71-82.

Bruns, A. (2008). Blogs, Wikipedia, Second Life, and beyond: From Production to Produsage. New York: Peter Lang.

Burgess, J. \& Green, J. (2009). YouTube. Cambridge: Polity.

Busch, T., Chee, F. \& Harvey, A. (2016). Corporate Responsibility and Gender in Digital Games. In Grosser, K., McCarthy, L. \& Kilgour, M. A. (eds.), Gender Equality and Responsible Business: Expanding CSR Horizons (pp. 31-45). Sheffield: Greenleaf Publishing.

Cater, N. (ed.) (2008) Technology, Cyberspace, \& Psyche. [Special issue]. Spring: A Journal of Art and Culture, 80.

Chen, C. (2016). Forming Digital Self and Parasocial relationships on YouTube'. Journal of Consumer Culture, 16(1): 232-254. 
Chess, S. \& Shaw, A. (2015). A Conspiracy of Fishes, or, How We Learned to Stop Worrying About \#GamerGate and Embrace Hegemonic Masculinity. Journal of Broadcasting \& Electronic Media, 59(1): 208-220.

Click, M. A., Lee, H. \& Holladay, H. W. (2013). Making Monsters: Lady Gaga, Fan Identification, and Social Media. Popular Music and Society, 36(3): 360-379.

Cooper, M. (2008). Essential Research Findings in Counselling and Psychotherapy: The Facts are Friendly. London: SAGE.

Cunningham, S., Craig, D. \& Silver, J. (2016). YouTube, Multichannel Networks and the Accelerated Evolution of the New Screen Ecology. Convergence: The International Journal of Research into New Media Technologies, 22(4): 376-391.

Davis, A. (2013). Promotional Cultures: The Rise and Spread of Advertising, Public Relations, Marketing and Branding. Cambridge: Polity.

Driessens, O. (2012). The Celebritization of Society and Culture: Understanding the Structural Dynamics of Celebrity Culture. International Journal of Cultural Studies, 16(6): 641-657.

Driessens, O. (2013). Celebrity Capital: Redefining Celebrity Using Field Theory. Theory and Society, 42(5): 543-560.

Dyer-Witheford, N. (1999). Cyber-Marx: Cycles and Circuits of Struggle in High Technology Capitalism. Champaign, IL.: University of Illinois Press.

Dyer-Witheford, N. (2010). Digital Labour, Species-becoming and the Global Worker. Ephemera: Theory \& Politics in Organization. Accessed 15. 07. 2016. URL: http://www.ephemerajournal.org/contribution/digital-labourspecies-becoming-and-global-worker.

Freud, S. (1911). Formulations Regarding the Two Principles of Mental Functioning. Papers on Metapsychology; Papers on Applied Psycho-Analysis. Vol. 4 of Collected Papers (pp. 13-21). London: Hogarth and Institute of PsychoAnalysis.

Fuchs, C. (2014). Digital Labour and Karl Marx. London: Routledge.

Fuchs, C. \& Sandoval, M. (eds.) (2014). Critique, Social Media and the Information Society. London: Routledge.

Fuchs C., Boersma, K. \& Albrechtslund, A. (eds.) (2012). Internet and Surveillance. The Challenges of Web 2.0 and Social Media. London: Routledge. 
Goffman, E. (1997). The Presentation of Self in Everyday Life. In Lemert, C. \& Branaman, A. (eds.) The Goffman Reader (pp. 95-108). Oxford: Blackwell. Griffin, E. (2006). A First Look at Communication Theory. Columbus, OH.: MacGraw Hill Education.

Gudykunst, W. (1995). Anxiety/Uncertainty Management (AUM) Theory: Current Status. In Wiseman, R. L. (ed.), Intercultural Communication Theory (pp. 8-58). Thousand Oaks, CA: SAGE.

Hauke, C. \& Alister, I. (eds.) (2000). Jung and Film: Post-Jungian Takes on the Moving Image. London Routledge.

Hauke, C. \& Hockley, L. (eds.) (2011). Jung and Film II -The Return: Further Post-Jungian Takes on the Moving Image. Hove: Routledge

Hill, A. (2014). Reality TV Experiences: Audiences, Fact, and Fiction. In Ouellette, L. (ed.), A Companion to Reality Television (pp. 116-133). Oxford: Wiley-Blackwell.

Hockley, L. (2007). Frames of Mind: A Post-Jungian Look at Cinema, Television and Technology. Bristol: Intellect.

Hockley, L. (2014). Somatic Cinema: The Relationship between Body and Screen - A Jungian Perspective. Hove: Routledge.

Hogan, B. (2010). The Presentation of Self in the Age of Social Media: Distinguishing Performances and Exhibitions Online. Bulletin of Science, Technology \& Society, 30(6): 377-386.

Jacoby, M. (2006). Individuation and Narcissism: The Psychology of Self in Jung and Kohut. London: Routledge.

Jenkins, H. (2006). Convergence Culture: Where Old and New Media Collide. New York: New York University Press.

Jenkins, H., Ito, M. \& boyd, d. (2015). Participatory Culture in a Networked Era. Cambridge: Polity.

Jerslev, A. (2014). Talking about Angelina - Celebrity Gossip on the Internet. Northern Lights, 12(1): 105-122.

Joinson, A. (2003). Understanding the Psychology of Internet Behaviour: Virtual Worlds, Real Lives. London: Palgrave Macmillan.

Jung, C. G. (1953). Two Essays on Analytical Psychology. New York: Pantheon Books.

Jung, C. G. (1971). Psychological Types. London: Routledge. 
Jung, C. G. (1921/1998). Psychological Types. In Storr, A. (ed.). The Essential Jung. London: Fontana.

Kohut, H. (1977). The Restoration of the Self. London: University of Chicago Press.

Kolhatkar, S. (2014, 26 November). The Gaming Industry's Greatest Adversary Is Just Getting Started. Bloomberg Businessweek. Accessed: 10. 01. 2017. URL: https://www.bloomberg.com/news/articles/2014-11-26/anita-sarkeesian-battles-sexism-in-games-gamergate-harassment.

Krüger, S. \& Johanssen, J. (2014). Alienation and Digital Labour - A DepthHermeneutic Inquiry into Online Commodification and the Unconscious. Triple C-Communication, Capitalism and Critique, 12(2): 632-647.

Lagore, J. (2015). Self-Promotion For All! Content Creation and Personal Branding in the Digital Age. In Coombs, D. S. \& Collister, S. (eds.), Debates for the Digital Age: The Good, the Bad, and the Ugly of Our Online World (pp. 221-240). Westport, CT.: Prager Publishers Inc.

Lashley, M. C. (2013). Making Culture on YouTube: Case Studies of Cultural Production on the Popular Web Platform. Doctoral Thesis. University of Georgia. Lange, P. G. (2014). Kids on YouTube: Technical Identities and Digital Literacies. Walnut Creek, CA.: Left Coast Press.

Lanier, J. (2013). Who Owns the Future? London: Allen Lane.

Learmonth, M. (2013, 2 May). Digitas Unveils Tool to Find YouTube Stars Before They're Stars: A Long Tail of YouTube Stars Is Out There But How to Find Them?. Advertising Age. Accessed 18. 07. 2016. URL: http://adage. $\mathrm{com} /$ article/special-report-tv-upfront/digitas-unveils-tool-find-nascentyoutube-stars/241262/.

Lemert, C. \& Branaman, A. (eds.) (1997). The Goffman Reader. Oxford: Blackwell.

Lovink, G. (2011). Networks without a Cause: A Critique of Social Media. Cambridge: Polity.

Lovink, G. (2016). Social Media Abyss: Critical Internet Cultures and the Force of Negation. Cambridge: Polity.

Lupton, D. (2016). The Quantified Self. Cambridge: Polity. MacCallum-Stewart, E. (2014). “Take That, Bitches!” Refiguring Lara Croft in Feminist Game Narratives. Game Studies, 14(2). Accessed: 10. 01. 2017. URL: http://gamestudies.org/1402/articles/maccallumstewart. 
Marcuse, H. (1955). Eros and Civilization: A Philosophical Inquiry into Freud. Boston: Beacon Press.

Marcuse, H. (1964). One Dimensional Man. London: Sphere Books.

Markos, E., Labrecque, L. I. \& Milne, G. R. (2012). Web 2.0 and Consumers'

Digital Footprint. Online Consumer Behavior: Theory and Research in Social

Media, Advertising and E-Tail, 157: 157-182.

Marshall, P. D. (2014). Celebrity and Power: Fame in Contemporary Culture. Minneapolis: University of Minnesota Press.

Meikle, G. \& Young, S. (2012). Media Convergence: Networked Digital Media in Everyday Life. London: Palgrave.

Papacharissi, Z. (2010). A Private Sphere. Cambridge: Polity.

Papacharissi, Z. (ed.) (2011). A Networked Self: Identity, Community and Culture on Social Network Sites. London: Routledge.

Poland, B. (2016). Haters: Harassment, Abuse, and Violence Online. Lincoln, MA.: Potomac Books.

Rojek, C. (2015). Presumed Intimacy: Para-Social Relationships in Media, Society and Celebrity Culture. Cambridge: Polity.

Shaw, A. \& Chess, S. (2016). Reflections on the Casual Games Market in a Post-GamerGate World. In Wilson, M. \& Leaver, T. (eds.), Social, Casual and Mobile Games: The Changing Gaming Landscape (pp. 277-290). London: Bloomsbury Academic.

Singh, G. (forthcoming). Death of Web 2.0: Ethics, Connectivity and Locked-in Psyche in the Twenty-First Century. London: Routledge.

Snickars, P. \& Venderau, P. (eds.) (2009). The YouTube Reader. London: Wallflower.

Spangler, T. (2014, 14 April). YouTube Multichannel Network was Target of Relativity's Surprise \$1.1 Billion Bid of Mostly Stock. Variety. Accessed 15. 07. 2016. URL: http://variety.com/2014/biz/news/relativity-offers-up-to900-million-for-maker-studios-in-bid-to-outflank-disney-1201156736/.

Sproull, L. \& Kiesler, S. (1986). Reducing Social Context Cues: Electronic Mail in Organizational Communications. Management Science, 32(11): 1492-1512.

Stever, G. S. (2011). Fan Behavior and Lifespan Development Theory: Explaining Para-social and Social Attachment to Celebrities. Journal of Adult Development, 18(1): 1-7. 
Stewart, C. T. (2008). Dire Emotions and Lethal Behaviours: Eclipse of the Life Instinct. Hove: Routledge.

Stuart, K. (2014, 3 December). Zoe Quinn: "All Gamergate has done is ruin people's lives". The Guardian. Accessed: 10. 01. 2017. URL: https://www. theguardian.com/technology/2014/dec/03/zoe-quinn-gamergate-interview.

Turkle, S. (2011). Alone Together: Why We Expect More from Technology and Less From Each Other. New York: Basic Books

Van Dijck, J. (2013). The Culture of Connectivity: A Critical History of Social Media. Oxford: Oxford University Press.

Vannoy Adams, M. (2004). The Fantasy Principle: Psychoanalysis of the Imagination. Hove: Brunner-Routledge.

Walker Rettberg, J. (2008). Blogging. Cambridge: Polity.

Walker Rettberg, J. (2014). Seeing Ourselves Through Technology: How We Use Selfies, Blogs and Wearable Devices to See and Shape Ourselves. London: Palgrave Macmillan.

Weitz, P. (ed.) (2014). Psychotherapy 2.0: Where Psychotherapy and Technology Meet. London: Karnac.

Winnicott, D. W. (1956). On Transference. International Journal of Psychoanalysis, 37: 386-388.

Zelenkauskaite, A. (2016). Remediation, Convergence, and Big Data: Conceptual Limits of Cross-platform Social Media. Convergence, The International Journal of Research into New Media Technologies, 22(1): 1-16.

\section{Acknowledgements}

My thanks go to Dr Eddy Borges Rey at the University of Stirling for taking the time to check through the drafts for this article, and also to Prof Luke Hockley for his generous comments. A special note of thanks to Rachel Hyndeman for her excellent undergraduate and postgraduate work, and giving me the benefit of her expertise regarding chat forums - without those discussions, this article would have been discernibly poorer. My thanks also extend to the anonymous peer-reviewers working for the journal who gave such generous commentary on earlier drafts. And of course, thanks to the Guest Editors of this special issue for inviting me to contribute. 